\title{
Das particularidades de tradução das versões ibéricas de Merlin e da sua
} suite $^{1}$

\author{
Simona Ailenii \\ Universidade "Alexandru Ioan Cuza" de Iași (SMELPS/IF)
}

Data de recepción: 23/05/2019 | Data de aceptación: 27/09/2019

\begin{abstract}
Resumo:
Neste trabalho propõe-se uma análise comparatista entre as versões da estória de Merlin da Península Ibérica. Devido a algumas particularidades textuais, as versões conhecidas até hoje foram situadas em ramos distintos do stemma codicum da obra. Os instrumentos da nossa análise são os textos derivados do processo de tradução, o galego-português (ms. 2434, BC) e os espanhóis (Salamanca, 1469; Burgos, 1498; Sevilha, 1535), em paralelo com os correspondentes franceses (ed. A. Micha, ed. O. Sommer, ed. G. Paris \& J. Ulrich, ed. G. Roussineau). Dado o carácter fragmentário materialmente e/ou textualmente tanto nas versões francesas, como nas ibéricas, esta análise basear-se-á somente nas narrativas comuns. Observar-se-ão, assim, algumas peculiaridades textuais resultantes do acto de tradução, no sentido de estudar as técnicas de tradução utilizadas e as circunstâncias que as determinam, tendo, ao mesmo tempo, em mente os parâmetros da distância temporal que separam os testemunhos e/ou os meios de transmissão (manuscrita, por um lado, e impressa, por outro).
\end{abstract}

\section{Palavras-chave:}

Merlin, francês, galego-português, castelhano, tradução, comparação.

\section{On the particularities of the Iberian versions of Merlin and his suite}

\begin{abstract}
:
This paper presents a comparative analysis of the versions of the Merlins'estoria from the Iberian Peninsula. Due to some textual particularities, they are divided into distinct branches of stemma codicumn. The instruments of the analysis are the gacilian-portuguese version (ms. 2434, BC) and the spanish versions from Salamanca (1469), Burgos (1498) and Sevilha (1535), in parallel with the french counterparts (ed. A. Micha, ed. O. Sommer,
\end{abstract}

1 Este trabalho desenvolve-se no âmbito do projecto "El ciclo artúrico de la Post-Vulgate puesto en cuestión: la naturaleza del modelo y la relación entre los derivados ibéricos reconsideradas", Proyecto I + D de Excelencia, convocatoria 2016, núm. FFI2016-78203-P. 
ed. G. Paris-J. Ulrich, ed. G. Roussineau). Given the fragmentary character of the french and iberian versions, from the material and/or textual point of view, this analysis is based only on common narratives. Several textual particularities, considered as a result of the translation act, show the tendencies of the time or of the cultural environment in which they were produced. Also, our goal is to study the translation techniques, the circumstances in which they were chosen, considering the temporal distance parameters which divide the testimonies and/or the ways of their transmission (manuscript, on one hand, and printed, on the other hand).

\section{Key words:}

Merlin, French, Galician-Portuguese, Castilian, translation, comparative analysis. 
A obra Merlin conhece, desde a sua génese no domínio românico, várias interpretações linguístico-estilísticas transmitidas tanto pela tradição manuscrita, como pela tradição impressa. Começando pelas origens textuais desta matéria, ou seja, pela trilogia de Robert de Boron, sabemos que dela se preservam², em verso, um Joseph d'Arimathie, um Merlin fragmentário e ainda uma prosificação e amplificação deste e, por fim, um Perceval em prosa. A lendária figura de Merlin continuará a ser tratada nas primeiras duas décadas do século XIII, no solo francês, num primeiro ciclo em prosa intitulado, pela crítica literária, Vulgata. Sabe-se que a versão prosificada de Merlin de Robert de Boron ${ }^{3}$ conhece duas continuações ${ }^{4}$. Uma primeira contida no ciclo Vulgata, em que se narra a história do mago e dos primeiros anos do reinado de Artur, e a segunda não tardará muito a aparecer, porque os homens da Idade Média, na década seguinte, 1230-1240, produzirão um segundo ciclo em prosa conhecido pela designação Pseudo-Robert de Boron ${ }^{5}$ ou Post-Vulgata ${ }^{6}$. Este ciclo constituirá uma versão expandida ou condensada, de acordo com diferentes estudiosos que se debruçaram sobre o tema. Assim, a configuração desta nova constituição cíclica do romance arturiano foi objecto de estudo de duas importantes teses da área. Referimo-nos ao trabalho de 1966, intitulado The Romance of the Grail, de Fanni Bogdanow ${ }^{7}$ e ao estudo de 1998, dedicado à Demanda do Santo Graal e ao Ciclo da Vulgata, de José Carlos Miranda ${ }^{8}$. Em ambas as organizações cíclicas, a Estoire de Merlin e as suas suites ocupam a segunda posição.

2 Gutiérrez García, Santiago (1997), Merlín e a sua historia, Vigo, Edicións Xerais, pp. 14-15.

3 Cf. Boron, Robert de (ed. 1979), Merlin. Roman du XIIIème siècle, Alexandre Micha (ed.), Genève, Librairie Droz.

4 Micha, Alexandre (1957), "Fragment de la Suite-Huth du Merlin", Romania, 78, p. 37.

5 A designação Pseudo-Robert de Boron da segunda constituição cíclica baseia-se no facto de vários romances desta reescrita do ciclo, nomeadamente a parte da Suite du Roman de Merlin, atribuirem a sua autoria a Robert de Boron. Cf. Laranjinha, Ana Sofia (2012), "A matéria tristaniana do ciclo do Pseudo-Boron, da Suite du Merlin à Demanda do Santo Graal”, De cavaleiros e cavalarias. Por terras de Europa e Américas, Lênia Márcia Mongelli (org.), São Paulo, Humanitas, pp. 101, n. 1; 107-108.

6 Bogdanow, Fanni (1966), The Romance of the Grail, New York, Manchester University Press, Barnes/ Noble, INC; Miranda, José Carlos (1998), A Demanda do Santo Graal e o Ciclo Arturiano da Vulgata, Porto, Granito.

7 Bogdanow, Fanni (1966), op. cit.

8 Miranda, José Carlos (1998), op. cit. 
A Suite du Roman de Merlin ${ }^{9}$, ou seja, a segunda suite, retoma e continua, segundo vários estudos ${ }^{10}$ sobre o tema, o Merlin em prosa de Robert de Boron, oferecendo-lhe um tratamento distinto da suite da Vulgata.

Em relação aos meios de transmissão, no domínio francês, trata-se de uma tradição manuscrita da obra, no âmbito da qual, Alexandre Micha ${ }^{11}$ inventaria quarenta e seis manuscritos completos e nove fragmentos franceses em que se transmitem o Merlin e as suites, testemunhos que representam quer a versão Vulgata, quer a versão Pseudo-Robert de Boron destes. No contexto peninsular ibérico, estão presentes tanto a tradição manuscrita, como a impressa, mas numa incomparável menor representatividade material. Conservam-se, em galego-português ${ }^{12}$, um único testemunho pergamináceo, datado do século XIV, em castelhano, um outro manuscrito miscelâneo em papel, datado de $1469^{13}$, e dois testemunhos da tradição impressa da obra, datados de $1498^{14}$ e $1535^{15}$. São testemunhos derivados através do acto de tradução e/ou de adaptação em contextos ideológicos distintos e, segundo vários estudiosos ${ }^{16}$, além de marcarem a difusão rápida da obra no espaço ibérico, tendo em cálculo a datação da primeira metade do século XIV do manuscrito galegoportuguês, representam versões pertencentes ao ciclo Pseudo-Robert de Boron.

9 Cf. Paris, Gaston \& Ulrich, Jacob (eds. 1886), Merlin, roman en prose du XIII siècle publié avec la mise en prose du poème de Robert de Boron d'après le manuscrit appartenant à M. Alfred Huth, Paris, Librairie de Firmin Didot et Cie; Roussineau, Gilles (ed. 1996), La Suite du Roman de Merlin, 2 voll., Genève, Librairie Droz.

10 Micha, Alexandre (1957), op. cit.; Roussineau, Gilles (ed. cit. 1996), pp. IX-CXXVIII; Morros, Bienvenido (1988), "Los problemas ecdóticos del Baladro del sabio Merlín", Actas del I Congresso de la Associanión Hispánica de Literatura Medieval, Vicente Beltrán (ed.), Barcelona, PPU, pp. 457-471; Laranjinha, Ana Sofia (2012), op. cit.

11 Micha, Alexandre (1957), op. cit.; Boron, Robert de (ed. cit. 1979), pp. XIV-LII.

12 Cf. PhiloBiblon, BITAGAP, manid 1604, http://bancroft.berkeley.edu/philobiblon/search_po.html (2.V.2019).

13 García de Lucas, César (1997), La Materia de Bretaña del Manuscrito 1877 de la Biblioteca Universitaria de Salamanca, Dissertação de doutoramento, Alcalá, Universidad de Alcalá, pp. L-LIV; PhiloBiblion, BETA, manid 2528, http://bancroft.berkeley.edu/philobiblon/searchwork_po.html (2.V.2019).

14 PhiloBiblon, BETA, manid 1196, http://bancroft.berkeley.edu/philobiblon/searchwork_po.html (2.V.2019); Bishop, Tracy Van (2002), A Parallel Edition of the Baladro del sabio Merlin: Burgos 1498 and Seville 1535. A dissertation submitted in partial fulfillment of the requirements for the degree of Doctor of Philosophy (Spanish) at the University of Wisconsin-Madison.

15 PhiloBiblon, BETA, manid 4157, http://bancroft.berkeley.edu/philobiblon/searchwork_po.html (2.V.2019); Bishop, Tracy Van (2002), op. cit.

16 Ailenii, Simona (2019), A tradução galego-portuguesa do romance arturiano. Os primeiros testemunhos, Porto, Estratégias Criativas; Gutiérrez García, Santiago, (2015), "Arthurian Literature in Portugal", The Arthur of the Iberians. The Arthurian Legends in the Spanish and Portuguese Worlds, David Hook (ed.), Cardiff, University of Wales Press, pp. 58-82. 
Considerando os meios distintos de transmissão da obra arturiana, manuscrita e impressa, conforme José Ramón Trujillo ${ }^{17}$, é imprescindível considerar este factor como determinante na forma peculiar de cada testemunho estruturar o texto. Além disso, é ainda de notar o factor que diz respeito à distância temporal que separa os testemunhos. Referimo-nos à sua recepção em domínios linguístico-culturais distintos, bem como em arcos cronológicos igualmente distintos.

Tendo isto em mente, o nosso propósito é estudar, partindo da base textual manuscrita e impressa da obra, mecanismos de tradução e/ou de adaptação da matéria narrativa, a fim de delinear elementos para uma gramática da tradução e/ ou da adaptação do romance arturiano.

Para atingir os nossos objectivos, do domínio francês retemos quatro testemunhos que foram já editados. Trata-se, em primeiro lugar, da edição realizada por Alexandre Micha ${ }^{18}$, em 1979, designada Merlin. Roman du XIII ${ }^{\mathrm{èm}}$ siècle, baseada no manuscrito 747 da BNF, datado do século XIII; em segundo lugar, da edição realizada por Oskar Sommer ${ }^{19}$, em 1908, intitulada Lestoire de Merlin, contida no ms. 10292 de Londres, British Museum, datado do século XIV; em terceiro lugar, da transcrição parcial oferecida por Amadeu J. Soberanas ${ }^{20}$ ao manuscrito de Cambridge, datado do século XIV; e, em quarto lugar, da edição realizada por Gaston Paris e Ulrich Jakob ${ }^{21}$, em 1886, intitulada Merlin. Roman en prose $d u X I I I^{e}$ siècle, tendo como base o manuscrito Huth, com uma nova cota, Add. 38117, Londres, British Museum, datado do século XIV. Entre estes manuscritos, no derradeiro, estamos perante um testemunho que, além de uma cópia das prosificações de Joseph d'Arimathie e de Merlin de Robert de Boron ${ }^{22}$, transmite a segunda continuação de Merlin do ciclo Pseudo-Robert de Boron. Esta segunda continuação da obra será conhecida por Suite du Roman de Merlin. É, sem dúvida, um texto particular pela escassa representatividade material e, implicitamente, textual na tradição manuscrita e impressa, tanto no domínio francês, como no peninsular ibérico.

17 Trujillo, José Ramón (2014), "Literatura artúrica en la Península Ibérica: Cuestiones traductológicas y lingüísticas”, eHumanista, 28, p. 504.

18 Robert de Boron (ed. cit. 1979).

19 Sommer, Heinrich Oskar (ed. 1908), The Vulgate Version of the Arthurian Romances, vol. II Lestoire de Merlin, Washington, The Carnegie Institution of Washington.

20 Soberanas, Amadeu-J. (1979), "La version galaico-portuguaise de la Suite du Merlin”, Vox Romanica, 38, pp. 174-193.

21 Paris, Gaston \& Ulrich, Jacob (ed. cit. 1886).

22 Ibidem, pp. VII-VIII. 
Situando-nos ainda no âmbito linguístico francês, até ao início do século passado, esta parte era conhecida somente pela versão conservada no manuscrito Huth, acima mencionado pela cota nova Add. 38117, Londres, British Library. Em 1913, Heinrich Oskar Sommer ${ }^{23}$ publica um fragmento do manuscrito francês 112 da Biblioteca Nacional de França ${ }^{24}$, datado de fins do século XV, que transmite também uma parte final da Suite du Merlin. Mais tarde, em 1945, Eugène Vinaver identifica, no manuscrito Add. 7071 da Universidade de Cambridge, datado do século XIV, uma versão melhor do ponto de vista da sua composição e anterior, segundo o autor ${ }^{25}$, à do manuscrito Huth da Suite du Merlin. Sobre um outro testemunho incompleto da Suite $d u$ Merlin escreve, em 1957, Alexandre Micha ${ }^{26}$. Trata-se de um manuscrito composto por dois fólios do Arquivo Nacional de Siena que contêm um breve segmento narrativo do mesmo romance. O estudioso francês edita o texto em 1957 e data-o, pela escrita documentada no manuscrito, dos finais do século XIII ${ }^{27}$. Como se pode notar, além de representada em escassíssimos testemunhos materiais, a Suite du Merlin não se transmite integralmente em nenhum destes testemunhos conservados. Um outro fragmento da Suite du Merlin foi identificado na Biblioteca Comunale de Imola por Monica Longobardi ${ }^{28}$, em 1987, e um outro ainda, em Bologna ${ }^{29}$.

Em relação à parte textual ibérica, serão considerados o fragmento de Salaman$\mathrm{ca}^{30}$ e os dois impressos designados Baladro del sabio Merlín, da responsabilidade

23 Sommer, Heinrich Oskar (1913), "Die Abenteuer Gawains, Ywains und Le Morholts mit den drei Jungfrauen aus der Trilogie (Demanda) des Pseudo-Robert de Boron die Fortsetzung des Huth-Merlin nach der allein bekannten HS. Nr. 112 der Pariser National Bibliothek Herausgegeben", Beihefte zur Zeitschrift für romanische Philologie, 47, pp. 1-134. Disponível em http://gallica.bnf.fr/ark:/12148/ bpt6k24848j/f2.image.r=H+O+Sommer.langPT (2.V.2019).

24 A descrição exaustiva deste testemunho francês, realizada por Cedric Edward Pickford em 1960, é imprescíndivel para a compreensão do fenómeno da recepção desta matéria literária na época. "Ce manuscrit, le 112 du fonds français de la Bibliothèque Nationale à Paris, pourrait être décrit comme une somme de romans arthuriens en prose. Presque tous les principaux romans y sont représentés, soit par des fragments plus au moins longs, soit par des analyses". Cf. Pickford, Cedric Edward (1960), L'évolution du roman arthurien en prose vers la fin du Moyen Âge d'après le manuscrit 112 du fond français de la Bibliothèque Nationale, Paris, A. G. Nizet, p. 10.

25 Vinaver, Eugène (1949), "La genèse de la Suite du Merlin", Mélanges de Philologie romane et de Littérature médiévale offerts à Ernest Hoepffner, Paris, Belles Lettres, p. 299.

26 Micha, Alexandre (1957), op. cit.

27 Ibidem, p. 37.

28 Longobardi, Monica (1987), "Frammenti di codici in antico francese della Biblioteca Comunale di Imola”, Cultura Neolatina, 47, pp. 223-255.

29 Longobardi, Monica (1992), "Nuovi frammenti della Post-Vulgata: la Suite du Merlin, la Continuazione della Suite du Merlin, la Queste e la Mort Artu (con l'intrusione del Guiron)", Studi Mediolatini e Volgari, XXXVIII, pp. 118-155.

30 Ms. 1877, BUS. 
editorial de Bonilla y San Martín ${ }^{31}$ e de Tracy Van Bishop ${ }^{32}$. Enquanto para o texto galego-português, intitulado Livro de Merlin, serão utilizados tanto o manuscrito 2434 da Biblioteca da Catalunha, como a transcrição paleográfica do mesmo, realizada por um colectivo de investigação da Galiza dirigido por Pilar Lorenzo Gradín e José A. Souto Cabo ${ }^{33}$.

Por que razão o olhar tão atento também na parte da Suite du Merlin? Nos testemunhos mencionados, dos inventários francês e ibérico que contêm a obra, lê-se parcialmente a história da continuação do Merlin.

Ora, embora constituído por um meio fólio e um bifólio ${ }^{34}$, o caso galego-português individualiza-se do ponto de vista da sua textualidade, por conter duas narrativas que em nenhum outro testemunho, quer do domínio ibérico, quer do francês, se registam juntas ${ }^{35}$. Referimo-nos a duas passagens narrativas em que se relata a história de amor do príncipe Anasten contada por Merlin à Donzela do Lago e parcialmente a história das doze donzelas adeviadores. Estas narrativas são representadas, nos testemunhos das tradições manuscrita e impressa, francesa, galego-portuguesa e castelhana, que contemplam a matéria da Suite du Merlin, da forma seguinte:

\begin{tabular}{l|c|c}
\multicolumn{1}{c|}{ Testemunhos } & \multicolumn{2}{|c}{ Narrativas } \\
& $\begin{array}{c}\text { A história de amor do } \\
\text { príncipe Anasten contada por } \\
\text { Merlin à Donzela do Lago }\end{array}$ & $\begin{array}{c}\text { Parte do episódio da Roche } \\
\text { aux Pucelles, as doze } \\
\text { donzelas adeviadores }\end{array}$ \\
\hline Ms. 2434, BC (século XIV) & $\operatorname{sim}$ & sim \\
\hline $\begin{array}{l}\text { Ms. Huth (Add. 38117, Londres, } \\
\text { British Library, século XIV) }\end{array}$ & $\operatorname{sim}$ & - \\
\hline $\begin{array}{l}\text { Ms. de Cambridge (Add. 7071, Cam- } \\
\text { bridge University, século XIV) }\end{array}$ & $\operatorname{sim}$ & - \\
\hline
\end{tabular}

31 Bonilla y San Martín, Adolfo (ed. 1907), El baladro del Sabio Merlín, primera parte de la Demanda del Sancto Grial, Libros de caballerías. Primera parte: Ciclo artúrico, Madrid, Nueva Biblioteca de Autores Españoles 6 (réédition de l'édition de Séville, 1535).

32 Bishop, Van Tracy (2002), op. cit.

33 Lorenzo Gradín, P. \& Souto Cabo, J. A. et alii (eds. 2001), Livro de Tristan e Livro de Merlin. Estudio, edición, notas e glosario, Santiago de Compostela, Centro de Ramón Piñero para a Investigacións en Humanidades, Xunta de Galicia.

34 Ailenii, Simona (2019), op. cit.

35 Soberanas, Amadeu-J. (1979), op. cit., pp. 177-178.

36 Ms. 2434, Biblioteca da Catalunha; Lorenzo Gradín, P. \& Souto Cabo, J. A. et alii (ed. cit. 2001).

37 Paris, Gaston \& Ulrich, Jakob (ed. cit. 1886); Roussineau, Gilles (ed. cit. 1996).

38 Soberanas, Amadeu-J. (1979), op. cit., pp. 174-193.

Revista Galega de Filoloxía, 2019, 20: 11-33

ISSN 1576-2661 / e-ISSN 2444-9121 


\begin{tabular}{l|c|c}
\multicolumn{1}{c|}{ Testemunhos } & \multicolumn{2}{c}{ Narrativas } \\
$\begin{array}{l}\text { Impressos }(1498, \text { Burgos; 1535, } \\
\text { Sevilha) }\end{array}$ & sim & - \\
\hline Ms. fr. 112, BNF (1470) & & sim \\
\hline Ms. 1877, BUS (1469) & - & - \\
\hline $\begin{array}{l}\text { Fragmento de Siena (finais do } \\
\text { século XIII) }\end{array}$ & - & - \\
\hline $\begin{array}{l}\text { Fragmentos de Imola (ms. 135, } \\
\text { Imola, Biblioteca Comunale, AA25 } \\
\mathrm{n}^{\circ} 9 \text { (7)) e de Bologna }\end{array}$ & - & - \\
\hline
\end{tabular}

Em 1960, Fanni Bogdanow ${ }^{44}$ considera a Suite du Merlin, baseando-se nos testemunhos que a contemplam, uma obra que conhece três fases redaccionais. O fragmento de Siena ${ }^{45}$ situa-se mais perto do arquétipo perdido da obra, ao passo que o texto contido no manuscrito de Cambridge representa a segunda fase e os do manuscrito Huth e das duas edições do Baladro, uma terceira fase. O afastamento entre a segunda e a terceira fase é conferido pela supressão, segundo a autora, de longos episódios bélicos que fazem parte da redacção segunda ${ }^{46}$.

Os problemas ecdóticos do Baladro del sabio Merlín já foram objecto de estudo num trabalho de Bienvenido Morros de $1988^{47}$, em que o autor, partindo de um cotejo entre o texto comum aos impressos espanhóis e ao fragmento de Salamanca, conclui que são três versões de um único modelo.

Deste modo, tendo em conta a escassez da materialidade e, implicitamente, da descontinuidade textual representada nos testemunhos conhecidos, apresentamos, em primeiro lugar, alguns casos extraídos da parte inicial de Merlin contemplada em somente três dos testemunhos ibéricos referidos, a saber, os impressos

39 Bonilla y San Martín, Adolfo (ed. cit. 1907); Bishop, Tracy Van (2002), op. cit.

40 Roussineau, Gilles (ed. cit. 1996).

41 Ms. 1877, BUS, ff. 282v-296'; Pietsch, Karl (ed. cit. 1924-1925); García de Lucas, César (1997), op. cit.

42 Micha, Alexandre (1957), op. cit.

43 Longobardi, Monica (1987), op. cit.; Longobardi, Monica (1992), op. cit.

44 Bogdanow, Fanni (1960), "Essai de classement des manuscrits de la Suite du Merlin", Romania, 81, pp. 188-198.

45 Micha, Alexandre (1957), op. cit.

46 Bogdanow, Fanni (1960), op. cit., p. 189; Bogdanow, Fanni (1962), “The Spanish Baladro and the Conte du Brait", Romania, pp. 383-399.

47 Morros, Bienvenido (1988), op. cit. 
do Baladro e o manuscrito de Salamanca, e nos correspondentes franceses já mencionados. Referimo-nos à parte inicial do romance em que se relata o plano dos diabos, reunidos num congresso, de dar origem no mundo a um paralelo humano com poderes sobrenaturais, Merlin, bem como o nascimento do mago e o desenlace feliz do julgamento da mãe. Em segundo lugar, um outro elenco de casos serão seleccionados da parte da Suite du Merlin contida nos Baladros e no manuscrito galego-português, em paralelo com os correspondentes franceses ${ }^{48}$. Trata-se da passagem comum em que se narra a história do príncipe Anasten contada por Merlin à Donzela do Lago.

A análise da tradição manuscrita e impressa do romance arturiano revelou, conforme se referiu acima, várias fases redaccionais das obras contempladas. Estudando, num trabalho anterior ${ }^{49}$, os textos arturianos galego-portugueses resultados do acto de tradução, foi possível notar técnicas distintas de tradução e/ ou adaptação. O confronto da base material do domínio galego-português com a correspondente francesa conduziu à compreensão das especificidades decorrentes do acto de tradução nos primeiros, ou seja, o texto de chegada se revelou inovador face ao de partida ou, pelo contrário, se pautou por uma atitude de fidelidade. O confronto dos textos peninsulares, como a Estória do Santo Graal conservada num fragmento pergamináceo dos finais do século XIII - início do século XIV ${ }^{50}$ e numa cópia manuscrita integral do século XVI ${ }^{51}$, o Livro de Merlin e o Livro de Tristan, igualmente preservados em manuscritos fragmentários datados do século $\mathrm{XIV}^{52}$, com os correspondentes franceses, permitiu-nos detectar técnicas idênticas de tradução em todos. Assim, através dos mecanismos de ausência por redução e de reformulação sintética, ter-se-á procurado a contracção lexical de que decorre uma expressão económica, precisa, e, através do mecanismo de amplificação, ter-se-á tentado facilitar a compreensão do conteúdo original, nos casos em que este parece

48 Soberanas, Amadeu-J. (1979), op. cit.; Roussineau, Gillles (ed. cit. 1996).

49 Ailenii, Simona (2019), op. cit., pp. 218-364.

50 Dias, Aida Fernanda (2003-2006), “A matéria da Bretanha em Portugal: relevância de um fragmento pergamináceo", Revista Portuguesa de Filologia. Miscelânea de estudos in memoriam José G. Herculano de Carvalho, XXV, I, Clarinda Azevedo Maia \& Ana Cristina Macário Lopes \& Graça Maria Rio-Torto (coords.), Coimbra, Instituto de Língua e Literatura Portuguesas, Faculdade de Letras da Universidade de Coimbra, pp. 145-221; Ailenii, Simona (2019), op. cit., pp. 19-89; 377-419.

51 Cf. Castro, Ivo (1984), Livro de José de Arimateia: estudo e edição do cod. ANTT 643, Dissertação de doutoramento, Lisboa, Universidade de Lisboa; Miranda, José Carlos et alii (eds. 2016), Estória do Santo Graal. Livro Português de José de Arimateia, Porto, Estratégias Criativas.

52 Ailenii, Simona (2019), op. cit.; Pichel, Ricardo \& Varela Barreiro, Xavier (2017), "O fragmento galego-português do Livro de Tristam. Nova proposta cronolóxica e diatópica", Madrygal. Revista de Estudios Gallegos, 20, pp. 159-214. 
carecer de clareza ${ }^{53}$. Mostrou-se que a Estória do Santo Graal e o Livro de Merlin, nas porções de texto conservadas, se mantêm, de um modo geral, mais fiéis, no plano da forma, face aos textos franceses consultados do que o Livro de Tristan. Conforme se constatou, neste último, não só se operou uma redução sistemática de elementos relacionados com as cenas bélicas, como também não se mencionaram os escudeiros de Lancelot ${ }^{54}$. No seu todo, o texto tristaniano revelou-se mais redutor do que a Estória do Santo Graal e o Livro de Merlin, notando-se ausências de segmentos mais compósitos, o que nos levou a crer que estas modificações podem ter sido feitas em território peninsular no acto de tradução.

Com base na porção inicial comum aos testemunhos castelhanos, do paralelismo entre estes e os correspondentes franceses, é possível distinguir duas situações. Uma diz respeito à versão contida no manuscrito de Salamanca em que o texto lido parece resultar da abordagem mais literal na reprodução da sua fonte, tanto no plano da forma, como no plano do conteúdo. Uma segunda situação visa os impressos em que, além das técnicas de ausência por redução, no plano da forma, e de amplificação ou reformulação, no plano do conteúdo, é possível sublinhar a tendência para uma tradução mais literária, muito próxima do mecanismo de interpretação textual. Assim, nestas duas versões, parece que estamos perante a alternância entre uma tradução literária e uma tradução literal. Importante seria observar se há segmentos narrativos específicos em que se opera uma ou outra técnica de traduzir.

O que nos faz crer que nos testemunhos galego-portugueses e no castelhano manuscrito, além da liberdade de o tradutor/redactor reduzir alguns segmentos temáticos (cenas bélicas) ou elementos relacionados ao tema (os escudeiros), como acima se referiu, a literalidade do texto resultado face à sua fonte, representada hoje por cópias francesas, é igualmente sustentável. Enquanto nos impressos castelhanos, na porção do texto estudado em confronto com o testemunhado no manuscrito de Salamanca e as francesas nas edições citadas, se nota uma liberdade maior na forma de reproduzir o texto fonte. Podemos dizer que o conteúdo não é omisso, mas, no plano da forma, as versões, em várias ocasiões, oferecem uma distinta dimensão estilística ao texto. É igualmente válido que haja porções de texto em que as versões castelhanas impressas se aproximam, no plano da forma, da manuscrita de Salamanca e da dos correspondentes franceses, vindo ao encontro das teses em que se sustenta o carácter literal ou a proximidade entre as versões impressas e a do testemunho Huth ${ }^{55}$.

53 Ailenii, Simona (2019), op. cit., pp. 367-369.

54 Ibidem, pp. 300-301.

55 Bogdanow, Fanni (1960), op. cit. 
No plano dos factos, propomos observar, por um lado, o carácter literal ou literário das traduções face aos equivalentes franceses e, por outro, o carácter privativo dos derivados ibéricos relevado pelas lições portadoras de marcas de ausência e de amplificação.

(i)

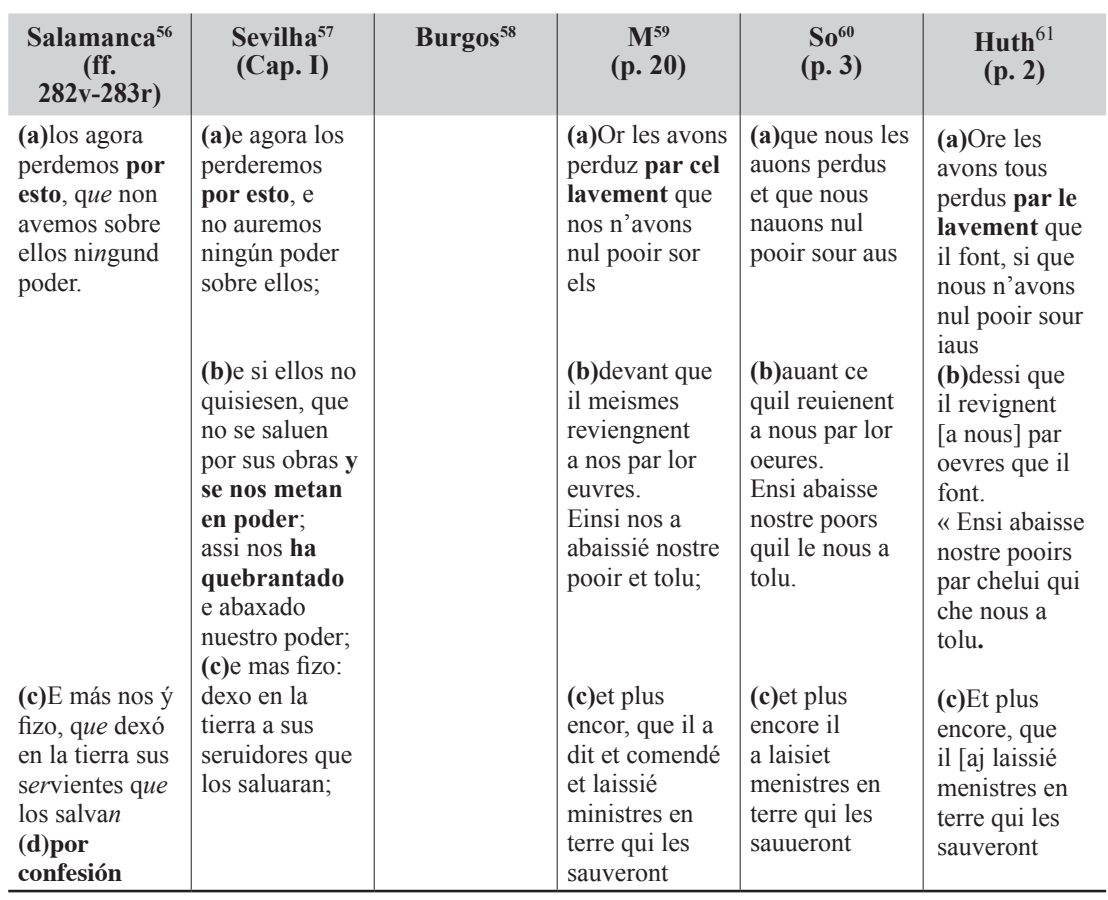

56 O texto de referência é do ms. 1877, BUS, que doravante será referido por Salamanca.

57 Será utilizado o texto da edição de Bonilla y San Martín, Adolfo (ed. cit. 1907) e da transcrição de Bishop, Van Tracy (2002), op. cit., doravante referido por Sevilha. Em relação à transcrição oferecida por Tracy Van Bishop, operaram-se algumas alterações que dizem respeito à separação de palavras e à transcrição da conjunção por "e".

58 Será utilizado o texto da transcrição de Bishop, Van Tracy (2002), op. cit., doravante referido por Burgos.

59 Será utilizada a edição da responsabilidade de Micha, Alexandre (ed. cit., 1979), doravante referida pela sigla $\mathrm{M}$.

60 Será utilizada a edição da responsabilidade de Sommer, Heinrich Oskar (ed. cit. 1908), doravante referida pela sigla So.

61 Será utilizada a edição da responsabilidade de Paris, Gaston \& Ulrich, Jakob (ed. cit. 1886), doravante referida por Huth. 
Como se pode ver na tabela acima, os trechos seleccionados sublinham dois aspectos. Em primeiro lugar, assinala-se o afastamento da versão lida no manuscrito de Salamanca face aos outros pela ausência do segmento (b), em que os diabos se mostram muito preocupados com a perda do poder sobre o ser humano, dada a purificação dos pecados através do acto do baptismo instituído por Jesus Cristo. Em segundo lugar, observa-se a literalidade dos testemunhos ibéricos nos segmentos comuns (a, c), além do sintetismo anafórico ${ }^{62}$ do elemento "por esto" interpretando o sintagma nominal "par le lavement" (a), equivalentes a todos os grupos verbais e nominais (a): "Or les avons perduz par cel lavement" (M), correspondendo a "los agora perdemos" (Salamanca), com a variante de Sevilha "e agora los perderemos"; ou "nous n'avons nul pooir sour iaus" (Huth), equivalente a "non avemos sobre ellos ningund poder" de Salamanca, com a variante de Sevilha "no auremos ningún poder sobre ellos". É, todavia, notável a tendência para a tradução mais livre ou mais explícita na versão impressa de Sevilha, em que as unidades "y se nos metan en poder" ou "nos ha quebrantado" (b) não encontram paralelo directo nos franceses. O segmento (d) mostra também o carácter singular, neste caso, da versão lida no manuscrito de Salamanca, pela lição explícita "por confesión", decorrida, o mais provavelmente, através do acto de tradução, dado que ulteriormente todas as versões castelhanas continuam a referir o acto de confissão: "e tantas non farán de nuestras obras que si ellos se confesaren ende e se quesieren quitar e arrepentir"63, com a variante de Sevilha "ya tantas no faran de las nuestras obras, si se confessasen, e se quisiesen ende quitar"

\begin{tabular}{|c|c|c|c|c|c|}
\hline $\begin{array}{l}\text { Salamanca } \\
\text { (f. 287v) }\end{array}$ & $\begin{array}{l}\text { Sevilha } \\
\text { (Cap. XI) }\end{array}$ & $\begin{array}{l}\text { Burgos } \\
\text { (Cap. II) }\end{array}$ & $\underset{\text { (p. 39) }}{M}$ & $\begin{array}{l}\text { So } \\
\text { (p. 9) }\end{array}$ & $\begin{array}{l}\text { Huth } \\
\text { (p. 13) }\end{array}$ \\
\hline (a)e santiguose & & & (a)si se seingna & (a)si se segna & $\begin{array}{l}\text { (a)Et quant elle } \\
\text { ot faict(e) le } \\
\text { signe de la crois }\end{array}$ \\
\hline $\begin{array}{l}\text { (b)e dixo: } \\
\text {-Sancta } \\
\underline{\text { Maria }} \text { ¿qué es } \\
\text { esto que así me } \\
\text { avino? Ca non } \\
\text { soy tal como } \\
\text { cuando me } \\
\text { aquí eché. }\end{array}$ & $\begin{array}{l}\text { (b)e dixo: } \\
\frac{\text {-Sancta }}{\text { Maria! ¿e que }} \\
\text { es esto que } \\
\text { agora assi me } \\
\text { catiuo? Ca no } \\
\text { soy agora tal } \\
\text { como quando } \\
\text { aqui me acoste. }\end{array}$ & $\begin{array}{l}\text { (b)e dixo: } \\
\text {-iSancta } \\
\text { Maria! ¿Que } \\
\text { es esto que } \\
\text { me asi agora } \\
\text { avino? Ca no } \\
\text { soy tal como } \\
\text { quando aqui } \\
\text { me acoste. }\end{array}$ & $\begin{array}{l}\text { (b)et dist : } \\
\text { «Sainte Marie, } \\
\text { que est ce qui } \\
\text { m'est avenu? } \\
\text { Je suis empiriee } \\
\text { de tel com } \\
\text { j'estoie quant je } \\
\text { me couchai. }\end{array}$ & $\begin{array}{l}\text { (b)et dist. } \\
\text { sainte marie } \\
\text { dame que est } \\
\text { ce que mest } \\
\text { auenu. ie sui } \\
\text { empirie de ce } \\
\text { que iestoie } \\
\text { quant ie me } \\
\text { couchai. }\end{array}$ & $\begin{array}{l}\text { (b)si dist : } \\
\text { «Dame sainte } \\
\text { Marie, que } \\
\text { m'est il avenu? } \\
\text { Je sui empirie } \\
\text { de tele comme } \\
\text { je soloie estre } \\
\text { quant je couchai } \\
\text { en che lit. }\end{array}$ \\
\hline
\end{tabular}

62 Cita-se o (con)texto anterior ao ilustrado na tabela (i): "E cuando los lavan a sus servientes dizen así: $<$ En el nonbre del Padre e del Fijo y del Spíritu Sancto. Amén>. E por esta razón nos los tuelle. E del peccado de Adán e de Eva que los devíamos de aver". Cf. Ms. 1877, BUS, f. $282^{v}$.

63 Ms. 1877, BUS, f. $283^{\text {r. }}$

64 Bonilla y San Martín, Adolfo (ed. cit. 1907), cap. I. 


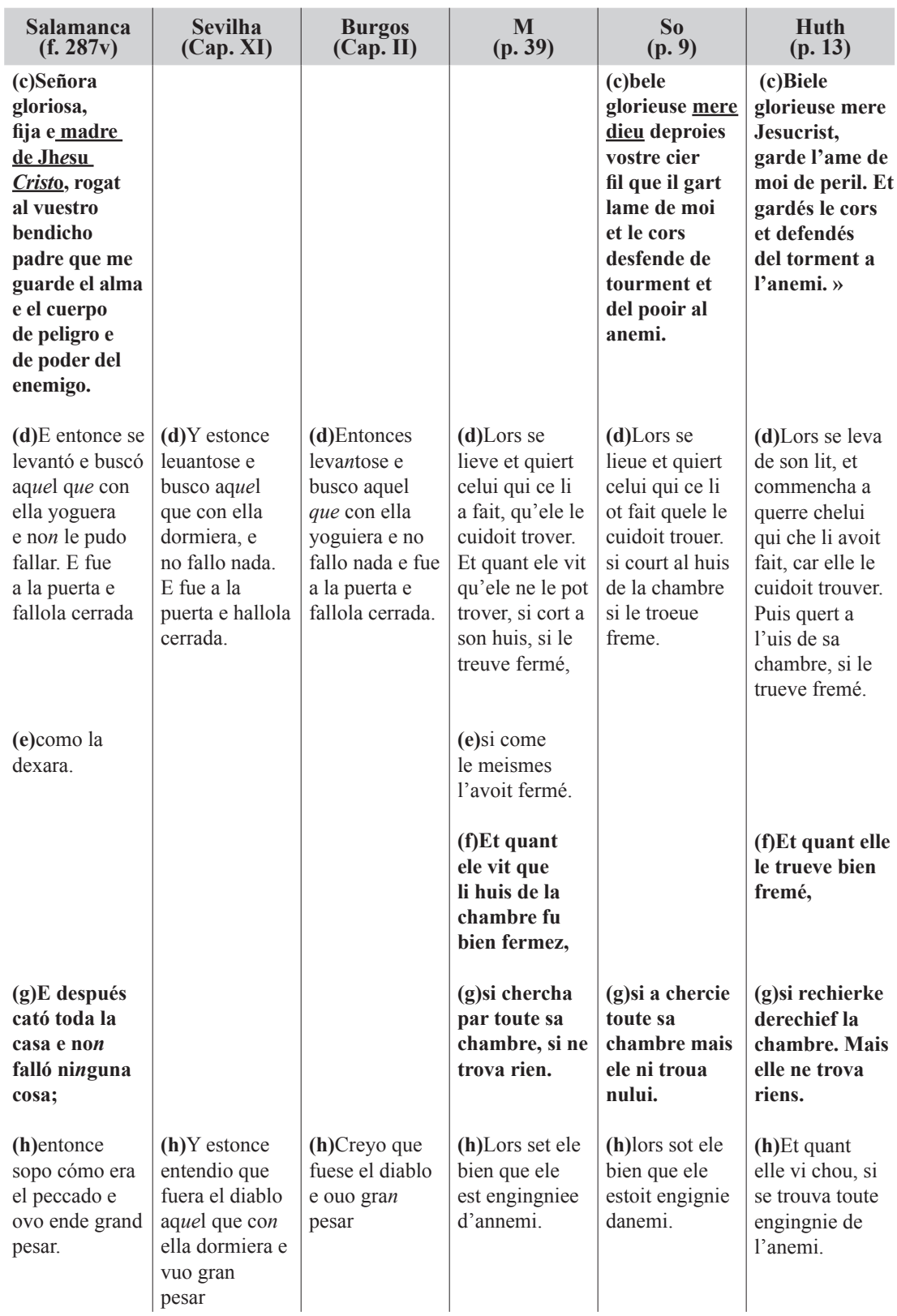




\begin{tabular}{|c|c|c|c|c|c|}
\hline $\begin{array}{l}\text { Salamanca } \\
\text { (f. 287v) }\end{array}$ & $\begin{array}{l}\text { Sevilha } \\
\text { (Cap. XI) }\end{array}$ & $\begin{array}{l}\text { Burgos } \\
\text { (Cap. II) }\end{array}$ & $\begin{array}{c}\text { M } \\
\text { (p. 39) }\end{array}$ & $\begin{array}{l}\text { So } \\
\text { (p. 9) }\end{array}$ & $\begin{array}{l}\text { Huth } \\
\text { (p. 13) }\end{array}$ \\
\hline $\begin{array}{l}\text { (i)E llamó al } \\
\text { Nuestro Señor }\end{array}$ & $\begin{array}{l}\text { (i)y } \\
\text { encomendose a } \\
\text { Dios. }\end{array}$ & $\begin{array}{l}\text { (i)e } \\
\text { acomendose a } \\
\text { Dios. }\end{array}$ & $\begin{array}{l}\text { (i)Lors } \\
\text { s'adolousa et } \\
\text { reclama molt } \\
\text { doucement } \\
\text { Nostre } \\
\text { Seingnor }\end{array}$ & $\begin{array}{l}\text { (i)si se } \\
\text { dolousa et } \\
\text { reclama moult } \\
\text { doucement } \\
\text { nostre signor }\end{array}$ & $\begin{array}{l}\text { (i)Lors se } \\
\text { commencha a } \\
\text { dementer et a } \\
\text { reclamer nostre } \\
\text { signeur, }\end{array}$ \\
\hline $\begin{array}{l}\text { (j)e rogo } \cdot \text { que } \\
\text { la non dexase } \\
\text { prender } \\
\text { escarnio en } \\
\text { este mundo. }\end{array}$ & & & $\begin{array}{l}\text { (j)et dist qu'il } \\
\text { ne la soufrist } \\
\text { a honir en cest } \\
\text { siecle. }\end{array}$ & $\begin{array}{l}\text { (j)et li prie } \\
\text { quil ne seuffre } \\
\text { ce que on le } \\
\text { hounie en cest } \\
\text { siecle. }\end{array}$ & $\begin{array}{l}\text { (j)et dist : } \\
\text { «Biaus sire } \\
\text { Dieus, par } \\
\text { vostre pitié, } \\
\text { sire, se il vous } \\
\text { vient a plaisir, } \\
\text { ne me laissiés } \\
\text { honnir en cest } \\
\text { siecle }\end{array}$ \\
\hline
\end{tabular}

O carácter fiel da versão de Salamanca face às francesas constata-se pelos registos assinalados no trecho acima destacado (ii), ao passo que a tendência para abreviação e quase interpretação livre do conteúdo original se pode notar nas versões impressas pela ausência dos segmentos (a), (c), (g), (j) ao longo da passagem em que se surpreende o desespero da filha do homem rico que não tardará muito a ter a grande missão de ser a mãe de Merlin. Estas abreviações podem ser marcas de um arquétipo comum, que deu origem a derivados sucessíveis com características distintas, ou há também a hipótese de resultarem do acto de tradução e/ou adaptação. Os registos que somente Salamanca retém, de acordo com os franceses, referem aspectos que enfatizam a ideologia cristã, como o sinal da cruz (a), a oração dirigida à Virgem (c), o rogo explícito da jovem face a "Nuestro Señor" (j), aspectos que concordam com o tema que une os textos seleccionados no manuscrito miscelâneo de Salamanca (Libro de la Vida de San Macario, Libro de la Vida de los Santos Padres, Libro de frey Juan de Rocacisa etc.) ${ }^{65}$. Ora, a ênfase destes aspectos, por não estarem contemplados nas versões castelhanas de Burgos e Sevilha, não deve ter tido o mesmo eco na fase impressa da tradução do texto sobre o nascimento de Merlin.

65 García de Lucas, César (1997), op. cit., pp. VI-IX. 
(iii)

\begin{tabular}{|c|c|c|c|c|}
\hline $\begin{array}{c}\text { Sevilha } \\
\text { (Cap. CCCXXV) }\end{array}$ & $\begin{array}{c}\text { Burgos } \\
\text { (Cap. XXXVIII) }\end{array}$ & $\begin{array}{c}\text { LM } \\
\text { (p. 151/ll. 3-5) }\end{array}$ & $\begin{array}{l}\text { Cambridge } \\
\text { (pp. 179-180) }\end{array}$ & $\begin{array}{c}\text { Huth }^{66} \\
\text { (§ 380/ll. 23-25) }\end{array}$ \\
\hline $\begin{array}{l}\text { e amauala tanto } \\
\text { aquel hijo del rey, } \\
\text { que quiso casar } \\
\text { con ella e tomola } \\
\text { por muger. }\end{array}$ & $\begin{array}{l}\text { e amavala tanto } \\
\text { aquel fijo del rey, } \\
\text { que quiso casar } \\
\text { con ella e tomarla } \\
\text { por muger. }\end{array}$ & $\begin{array}{l}\text { E amaua hũa } \\
\text { ffilha duum pobre } \\
\text { caualeyro de tan } \\
\text { grande amor } \\
\text { que nenhuu<..> } \\
\text { home nonpoderya } \\
<. . .>\text { mayor amor } \\
\text { a molher }\end{array}$ & $\begin{array}{l}\text { e amoit la fille } \\
\text { d'un povr [sic] } \\
\text { chevalier de si } \\
\text { grant amur } \\
\text { que morteuz home } \\
\text { ne porroit tant } \\
\text { femme amer }\end{array}$ & $\begin{array}{l}\text { Il amoit la fille d'un } \\
\text { povre chevalier de } \\
\text { si grant amour } \\
\text { que morteus hom } \\
\text { ne pooit plus feme } \\
\text { amer }\end{array}$ \\
\hline
\end{tabular}

(iv)

\begin{tabular}{|c|c|c|c|c|}
\hline $\begin{array}{c}\text { Sevilha } \\
\text { (Cap. CCCXXV) }\end{array}$ & $\begin{array}{c}\text { Burgos } \\
\text { (Cap. XXXVIII) }\end{array}$ & $\begin{array}{c}\mathbf{L M}^{67} \\
\text { (p. 151/ll. 9-12) }\end{array}$ & $\begin{array}{l}\text { Cambridge }^{68} \\
\text { (pp. 179-180) }\end{array}$ & $\begin{array}{l}\text { Huth }^{69} \\
\text { (§ 381/ll. 6-9) }\end{array}$ \\
\hline $\begin{array}{l}\text { Cierto, si te no } \\
\text { partes desta locu- } \\
\text { ra, yo te hare tal } \\
\text { escarnio } \\
\text { que nunca seas de } \\
\text { ver al mundo, } \\
\text { ca ella no es para } \\
\text { ser tu muger qual } \\
\text { tu deues auer, } \\
\text { e no ha cosa en el } \\
\text { mundo por que } \\
\text { querria que lo } \\
\text { fiziesses, } \\
\text { ca a mi me seria } \\
\text { muy gran deson- } \\
\text { ra y mengua; } \\
\text { e porque se que en } \\
\text { ello pensaste, } \\
\text { la fare matar". }\end{array}$ & $\begin{array}{l}\text { Cierto, si te partes } \\
\text { desta locura, yo } \\
\text { te faré tal escar- } \\
\text { miento, } \\
\text { que nunca seas } \\
\text { de ver } \\
\text { ca ella no es para } \\
\text { ser tu muger, } \\
\text { qual tú deves } \\
\text { aver, } \\
\text { e no ay cosa en el } \\
\text { mundo por qué } \\
\text { yo quisiese que lo } \\
\text { fizieses, } \\
\text { ca me seria a mi } \\
\text { grand vergüença, } \\
\text { e a ti mengua. } \\
\text { E porque sólo en } \\
\text { ello pensaste, la } \\
\text { faré matar. }\end{array}$ & $\begin{array}{l}\text { Se te non quitas } \\
\text { dessa conpanha. } \\
\text { eu } \\
\text { (a)matarey ty } \mid \text { ou| } \\
\text { ẹela. } \\
\text { (b)Matarme } \\
\text { podedes dissel. } \\
\text { mays eu non } \\
\text { quitarey ende. } \\
\text { ante a. amarey } \\
\text { senpre mentre eu } \\
\text { uyuer. Sy disse } \\
\text { el Rey. } \\
\text { ora saby queeu ty } \\
\text { (c)partyrey dela. } \\
\text { ca a } \\
\text { (d)matarey ante } \\
\text { ty. }\end{array}$ & $\begin{array}{l}\text {-Si tu ne lessasse } \\
\text { sa compaignie, } \\
\text { jeo te } \\
\text { (a)destruierai } \\
\text { od lui. } \\
\text {-Pur tant, fait il, // } \\
\text { me poez } \\
\text { (b)destruire, car } \\
\text { jeo ne lerrai ja, } \\
\text { ainz l'ameroit tote } \\
\text { ma vie. } \\
\text {-Voire, dist li rois, } \\
\text { ore sachiez que } \\
\text { jeo te } \\
\text { (c)destruierai et li } \\
\text { devant toi. }\end{array}$ & $\begin{array}{l}\text { "Se tu ne laisse } \\
\text { briement sa com- } \\
\text { paignie, je te } \\
\text { (a)destruirai." } \\
\text { Et il dist: "Je nel } \\
\text { lairai ja, } \\
\text { ains l'amerai toute } \\
\text { ma vie. } \\
\text {-Voire? che dist } \\
\text { li rois. } \\
\text { Or saches que je } \\
\text { t'en } \\
\text { (c)destruirai et li } \\
\text { devant toi." }\end{array}$ \\
\hline
\end{tabular}

66 Para esta porção de texto, será utilizada a edição de Rousineau, Gilles (ed. cit. 1996).

67 Será utilizada a edição da responsabilidade de Lorenzo Gradín, P. \& Souto Cabo, J. A. et alii (ed. cit. 2001), doravante referida pela sigla LM.

68 Será utilizado o texto transcrito por Soberanas, Amadeu-J. (1979), op. cit., doravante referido por Cambridge.

69 Para este trecho, será utilizado o texto da edição de Rousineau, Gilles (ed. cit. 1996). 
(v)

\begin{tabular}{|c|c|c|c|c|}
\hline $\begin{array}{c}\text { Sevilha } \\
\text { (Cap. CCCXXV) }\end{array}$ & $\begin{array}{c}\text { Burgos } \\
\text { (Cap. XXXVIII) }\end{array}$ & $\begin{array}{c}\text { LM } \\
\text { (p. 151/ll. 14-16) }\end{array}$ & $\begin{array}{l}\text { Cambridge } \\
\text { (pp. 179-180) }\end{array}$ & $\begin{array}{l}\text { Hut }^{70} \\
(\S 381 / \text { Il. 9-13) }\end{array}$ \\
\hline $\begin{array}{l}\text { Y el hijo fue tan } \\
\text { espantado, que } \\
\text { no supo dar con- } \\
\text { sejo; por tan gran } \\
\text { saña que auia con } \\
\text { su padre, penso } \\
\text { mas de guardar } \\
\text { la donzella, que } \\
\text { cuydo por esto que } \\
\text { la perderia; }\end{array}$ & $\begin{array}{l}\text { El fijo fué dello } \\
\text { tan espantado, } \\
\text { que no supo darse } \\
\text { consejo, e por la } \\
\text { gran saña que } \\
\text { veía en su padre, } \\
\text { pensó de guardar } \\
\text { más la donzella, } \\
\text { que creyó que la } \\
\text { perdería, }\end{array}$ & $\begin{array}{l}\text { Como anasten con } \\
\text { pauor de aSen seu } \\
\text { padre fez a camar } \\
\text { na pena } \\
\text { Qvando Anasten } \\
\text { isto ouuyu. ffez } \\
\text { asconder a don- } \\
\text { zela. } \\
\text { Que a non podesse } \\
\text { achar seu padre. }\end{array}$ & $\begin{array}{l}\text { Quant li che- } \\
\text { valiers oi ceste } \\
\text { novele, si fist la } \\
\text { damoisele destur- } \\
\text { ner e respondre } \\
\text { que ses peres ne le } \\
\text { trovast. }\end{array}$ & $\begin{array}{l}\text { Quant li chevaliers } \\
\text { entent ceste } \\
\text { nouviele, il fist la } \\
\text { damoisele destorner } \\
\text { et reponre, que ses } \\
\text { peres ne la trouvast. }\end{array}$ \\
\hline $\begin{array}{l}\text { y penso de se } \\
\text { esconder con ella }\end{array}$ & $\begin{array}{l}\text { e pensó de escon- } \\
\text { derse con ella. }\end{array}$ & $\begin{array}{l}\text { E pensou que } \\
\text { buscarya Alguu } \\
\text { logar estranho } \\
e \text { longe de toda } \\
\text { gente u nenguum } \\
\text { non morasse. }\end{array}$ & $\begin{array}{l}\text { E pensoit qu'il } \\
\text { queroit un lieu } \\
\text { estrange e long } \\
\text { de tut gent ou nul } \\
\text { repairoit }\end{array}$ & $\begin{array}{l}\text { Et pensa qu'il } \\
\text { querroit un lieu } \\
\text { estrange et loing de } \\
\text { toute gent, ou nus } \\
\text { ne repaireoit }\end{array}$ \\
\hline
\end{tabular}

No primeiro conjunto de casos (i, ii), estamos na parte inicial da estória sobre Merlin, atestada, na Península Ibérica, pelos três testemunhos castelhanos em cotejo. No segundo conjunto de casos (iii-v), situamo-nos na Suite du Merlin, testemunhada, no solo ibérico, no fragmento galego-português e nas versões impressas castelhanas. Se na primeira série de casos (i, ii), extraídos da parte inicial da estória, foi possível um paralelismo entre os testemunhos em cotejo, no conjunto seguinte (iii-v), seleccionado da parte que continua e desenvolve a estória de Merlin, teremos oportunidade de constatar o carácter mais literário da tradução castelhana, oposto ao literal da galego-portuguesa. Entre os testemunhos franceses em cotejo é possível manter o texto do manuscrito Huth e o do manuscrito de Cambridge, porque são os únicos manuscritos do espaço francês que contêm a respectiva passagem, como já referimos. Em relação ao mansucrito Huth, segundo a crítica textual ${ }^{71}$, a tradução castelhana mostra mais proximidade. À luz desta proximidade será observado o fenómeno de tradução na respectiva parte textual. Nos trechos seleccionados (iii-v), constata-se facilmente a literariedade, no plano da forma, destas versões face ao arquétipo atestado pelas edições francesas aqui colacionadas, enquanto a tradução galego-portuguesa se revela

70 Ibidem.

71 Bogdanow, Fanni (1960), op. cit.; Morros, Bienvenidos (1988), op. cit. 
um modelo de literalidade. Esta observação leva-nos a ponderar a hipótese de, nas versões impressas, o tratamento estilístico divergente ter sido incumbência do seu redactor, sendo a (re)escrita, na tradição impressa, igualmente um acto de (re)criação singular determinado pelos factores culturais e ideológicos da época ${ }^{72}$.

Quanto ao exemplo (iii), o texto de chegada lido na versão galego-portuguesa mostra uma tendência para a expressão em grupo nominal face ao verbal do texto de partida. O segmento "non poderya $<\ldots>$ mayor amor a molher" marca a utilização do nome "amor" em galego-português, correspondente do verbo "amer" nos testemunhos Huth/Cambridge ("ne pooit plus feme amer"/"ne porroit tant femme amer"). Neste caso, tratar-se-ia de uma mera preferência no texto de chegada pela expressão nominal. Nas versões castelhanas, os dois grupos verbais das orações "quiso casar con ella" e "tomola por muger" são portadores de marcas estilísticas explícitas da acção que se enfatiza pelo procedimento de redundância verbal ("casar" e "tomola por muger"). Estes exemplos podem ilustrar o princípio de equivalência dinâmica do acto de tradução que se centra amplamente no conteúdo do texto de partida.

Na quarta selecção, a menção sublinhada em primeiro lugar diz respeito às formas verbais "matar" - (a), (b) - e "partir" - (c) - que aparecem, no Livro de Merlin, como equivalentes de "destruire" dos testemunhos Huth - (a) - e Cambridge - (a), (b), (c) -, em todas as três ocorrências deste último ${ }^{73}$. Assim, o segmento verbal "eu matarey ty" (a) corresponde semanticamente à estrutura verbal "je te destruirai" de Huth/“jeo te destruierai" de Cambridge. O segundo, "Matarme podedes" (b), é equivalente a "me poez destruire", registado apenas no testemunho Cambridge, sendo o texto Huth omisso nesta ocorrência. De facto, no caso (b), este último testemunho regista uma sintaxe distinta dos outros dois, como se salienta na tabela (iv, a), pela omissão da correspondência da disjunção encontrada no Livro de Merlin, "|ou| ẹela", equivalente à lição "od ${ }^{74}$ lui" de Cambridge. Por outro lado, percorrendo individualmente o texto oferecido pelas três versões, lemos uma história coerente em cada um. Ou seja, no Livro e Merlin, o rei ameaça separar o príncipe da amiga pela morte de um deles, "eu matarey ty |ou| ẹela", e, no fim da passagem, descobrimos o plano concreto do rei quanto à tão desejada separação entre os dois amantes pela morte da amiga, "ca a matarey ante ty". Em Cambridge, lemos uma história parecida à do Livro galego-português, com uma diferença sintáctica no que respeita à relação entre os pronomes (te/ty, ela/lui) e, outra semântica, decorrida da anterior relação

72 Gutiérrez García, Santiago (2015), op. cit., p. 84.

73 Este trecho foi objecto de estudo comparativo somente entre a versão do testemunho galego-português e as dos dois franceses aqui contemplados em Ailenii, Simona (2019), op. cit., pp. 251 sqq.

74 Dictionnaire Godefroy regista o significado "avec" da preposição "od” (< lat. apud). Disponível em http://www.lexilogos.com/francais_dictionnaire_ancien.htm (30.I.2019). 
sintáctica que, logicamente, determina outro plano semântico. Ora, os pronomes pessoais com função sintáctica diferente, um de complemento de objecto directo, "te", e outro de complemento de companhia, "od lui", encontram-se em Cambridge, ("jeo te destruirai od lui"), enquanto no Livro ibérico, os dois pronomes têm um uso sintáctico de complementos directos em relação de disjunção coordenativa ("eu matarey ty |ou| ẹela"). E, no tocante ao desacordo semântico, em Cambridge, tendo em conta que não se trata sintacticamente da disjunção lida em galego-português, mas de complementos distintos, pode concluir-se que o rei planeia a morte dos dois amantes ("jeo te destruirai et li devant toi"). Enquanto em Huth, a primeira ameaça visa apenas a vida do príncipe (“je te destruirai”), ao contrário do que lemos nos primeiros dois textos comentados e, no final, anuncia o seu plano de os separar pela morte dos dois ("je t'en destruirai et li devant toi”). Consistiria isto num tratamento linguístico-estilístico distinto derivado através da tradição manuscrita do texto, tratamento que pode ser indício de relação de filiação entre as versões do texto.

Uma situação (c) vem mostrar, do ponto de vista do estudo de tradução, como a atenção do tradutor se centra, preferencialmente, na expressão explícita de determinadas acções. A utilização dos núcleos verbais do segmento "eu ty partyrey dela. ca a matarey ante ty", como equivalentes a "je t'en destruirai et li devant toi" em Huth, "jeo te destruierai et li devant toi” em Cambridge, mostra a variação lexical da língua receptora pela correspondência entre o francês "destruire" e o português "partir" e, ao mesmo tempo, uma diferença no plano semântico. Ou seja, o texto de chegada indica o plano de o rei separar o príncipe da sua amante pela morte desta, enquanto os testemunhos franceses sugerem, pela conjugação do mesmo verbo em dois (Huth), respectivamente três (Cambridge) contextos seguidos, "destruire", a morte dos dois amantes causada pelo rei.

Tratar-se-ia, provavelmente, de novo, de uma coerência textual produzida no acto de tradução, porque, afinal, a espada do rei mata efectivamente apenas a "amjga" do príncipe. Mas não deixa de ser relevante o que a história nos revela em relação ao destino dos dois, porque "quando morreron que morreron anbos" ${ }^{75}$, caindo o príncipe em grande desgosto depois de constatar o plano letal do rei em relação à sua amada.

A versão castelhana impede um paralelismo directo dos elementos acima indicados e realizáveis entre a versão galego-portuguesa e as francesas, masválido é que, no plano do conteúdo, lemos uma história similar, com a constatação da menor acentuação na acção de matar ou "destruir", um ou outro, da parte do rei, mas da ênfase que se dá aos aspectos ligados à ética da nobreza no domínio do matrimónio:

75 Cf. Lorenzo Gradín, P. \& Souto Cabo, J. A. et alii (ed. cit. 2001), p. 152/1. 25. Para outros assuntos relacionados com as possíveis fontes literárias dos episódios que os testemunhos peninsulares transmitem, ver Gutiérrez García, Santiago (2015), op. cit., pp. 82-86. 
“ca ella no es para ser tu muger, qual tú deves aver, e no ay cosa en el mundo por qué yo quisiese que lo fizieses, ca me seria a mi grand vergüença, e a ti mengua" (iv).

No que respeita à quinta tabela, evidencia-se, em primeiro lugar, em relação ao paralelismo entre a versão galego-portuguesa e as francesas, que, no texto de chegada, se utiliza a expressão mais económica, sem afectar o plano semântico, pelo uso da forma anafórica "isto", substituindo o grupo nominal "ceste nouviele". No mesmo racionício da economia textual e da explicitação, chama-se também a atenção para a designação do príncipe pelo nome próprio "Anasten", enquanto o texto francês utiliza o nome "li chevaliers". A utilização do nome próprio na referência à personagem pode ser justificada pela cisão que a interpolação da rubrica cria textualmente (v). Se no Livro de Merlin se optasse por manter o equivalente directo do francês "li chevaliers", resultaria, na economia textual, uma lição confusa; mas o nome próprio "Anasten” exprime, de uma forma clara, o sujeito desta oração que, aliás, é antecipado pela rubrica. No caso da anáfora, trata-se, a nosso ver, de uma opção pela brevidade resultante do acto de tradução. No texto receptor, recorre-se à expressão anafórica, a fim de obter uma redacção económica da fonte francesa. Nas traduções, vemos o uso abundante deste tipo de expressão como característica decorrida do acto de tradução.

A versão castelhana, lida nos testemunhos de Sevilha e Burgos, oferece uma tradução livre (v), colocando maior ênfase nos aspectos psicológicos ("Y el hijo fue tan espantado [...] por gran saña que auia con su padre" de Sevilha; "El fijo fué dello tan espantado [...] e por la gran saña ${ }^{76}$ que veía en su padre" de Burgos), o que nos faz pensar que, nesta porção de texto, a literalidade da versão castelhana é diminuida face ao testemunho francês Huth, por exemplo, com o qual habitualmente se afina.

Em conclusão, podemos dizer que a versão castelhana impressa privilegia a literariedade em algumas porções de texto, o que se poderá interpretar como marca cultural e ideológica da recepção do texto. Há claramente uma tendência geral, nas traduções, para a contracção da estrutura lexical, a concisão, a ênfase de aspectos distintos. Apesar de o texto de chegada não seguir constantemente o princípio da correspondência formal do texto de partida, observamos que, no fundo, os receptores dos três textos têm acesso a uma narrativa similar, com apenas alguns elementos estilísticos divergentes.

O fenómeno de adaptação pode privilegiar uma organização textual mais coerente face à matéria narrativa da fonte, pondo em relevo os meios gramaticais e estilísticos da língua de destino e/ou pode ajustar-se às condicionantes culturais e ideológicos da época e da tradição de transmissão. A técnica de reformulação por anáfora, bem como a de redução devem evidenciar o carácter económico do texto receptor.

76 Sublinhados nossos. 


\section{Referências bibliográficas}

\section{Siglas utilizadas}

$\mathrm{BC}$ - Biblioteca da Catalunha

BUS - Biblioteca Universitária de Salamanca

BNF - Biblioteca Nacional de França

\section{Manuscritos}

Ms. 2434, Biblioteca da Catalunha.

Ms. 1877, Biblioteca Universitária de Salamanca, ff. 282 $-296^{\mathrm{r}}$.

\section{Edições}

Bonilla y San Martín, Adolfo (ed.) (1907). El baladro del Sabio Merlín, primera parte de la Demanda del Sancto Grial, Libros de caballerías. Primera parte: Ciclo artúrico. Madrid: Nueva Biblioteca de Autores Españoles 6 (Réédition de l'édition de Séville, 1535).

Boron, Robert de (1979). Merlin. Roman du XIII ${ }^{\text {ème }}$ siècle. Ed. de Alexandre Micha. Genève: Librairie Droz.

Lorenzo Gradín, P. \& Souto Cabo, J. A. (eds.) (2001). Livro de Tristan e Livro de Merlin. Estudio, edición, notas e glosario. Santiago de Compostela: Centro de Ramón Piñero para a Investigacións en Humanidades / Xunta de Galicia.

Miranda, José Carlos et alii (eds.) (2016). Estória do Santo Graal. Livro Português de José de Arimateia. Porto: Estratégias Criativas.

Paris, Gaston \& Ulrich, Jacob (eds.) (1886). Merlin, roman en prose du XIII siècle publié avec la mise en prose du poème de Robert de Boron d'après le manuscrit appartenant à $M$. Alfred Huth. Paris: Librairie de Firmin Didot et $C^{\text {ie }}$.

Pietsch, Karl (ed.) (1924-1925). Spanish Grail Fragments: El Libro de Joseph Abarimathia, la Estoria de Merlin, Lançarote, 2 voll. Chicago: University Press, The Modern Philology Monograpfs of the University of Chicago.

Roussineau, Gilles, (ed.) (1996). La Suite du Roman de Merlin, 2 voll. Genève: Librairie Droz.

Sommer, Heinrich Oskar (ed.) (1908). The Vulgate Version of the Arthurian Romances, vol. II Lestoire de Merlin. Washington: The Carnegie Institution of Washington. 


\section{Estudos}

Ailenii, Simona (2019). A tradução galego-portuguesa do romance arturiano. Os primeiros testemunhos. Porto: Estratégias Criativas.

Ailenii, Simona (2017). “Tradução peninsular das estórias do Santo Graal, Merlin e Tristan”. Em Rafaela da Câmara Silva (ed.), Doiro antr'o Porto e Gaia. Estudos de Literatura Medieval Ibérica, 135-150. Porto: Estratégias Criativas.

Ailenii, Simona (2013). "A tradução galego-portuguesa do romance arturiano nos séculos XIII e XIV”. E-Spania - Revue interdisciplinaire d'études hispaniques médiévales et modernes, nr. 16 / décembre 2013. Disponível em http://e-spania. revues.org/22611\#entries (30.I.2019).

Bishop, Tracy Van (2002). A Parallel Edition of the Baladro del sabio Merlin: Burgos 1498 and Seville 1535, 73-983. A dissertation submitted in partial fulfillment of the requirements for the degree of Doctor of Philosophy (Spanish) at the University of Wisconsin-Madison.

Bogdanow, Fanni (1966). The Romance of the Grail. New York: Manchester University Press, Barnes/Noble, INC.

Bogdanow, Fanni (1962). "The Spanish Baladro and the Conte du Brait". Romania, 83, 331 (3), 383-399.

Bogdanow, Fanni (1960). "Essai de classement des manuscrits de la Suite du Merlin". Romania, 81, 188-198.

Bogdanow, Fanni (1979). "The Suite du Merlin and the Post-Vulgate Roman du Graal”. Em Roger Sherman Loomis (ed.), Arthurian Literature in the Middle Ages. Oxford, Clarendon Press, 325-335.

Castro, Ivo (1984). Livro de José de Arimateia: estudo e edição do cod. ANTT 643. Dissertação de doutoramento. Lisboa: Universidade de Lisboa.

Dias, Aida Fernanda (2003-2006). "A matéria da Bretanha em Portugal: relevância de um fragmento pergamináceo". Revista Portuguesa de Filologia. Miscelânea de estudos in memoriam José G. Herculano de Carvalho, XXV, I, 145-221.

García de Lucas, César (1997). La Materia de Bretaña del Manuscrito 1877 de la Biblioteca Universitaria de Salamanca, 2 voll. Dissertação de doutoramento. Alcalá: Universidad de Alcalá.

Gracia, Paloma (2007). "Los Merlines castellanos a la luz de su modelo subyacente: la Estoria de Merlín del ms. 1877 de la Biblioteca Universitaria de Salamanca". Em Juan Manuel Cacho Blecua (coord.), De la literatura caballeresca al Quijote, 233-248. Zaragoza: Prensas Universitarias de Zaragoza.

Gutiérrez García, Santiago (1997). Merlín e a súa historia. Vigo: Edicións Xerais. 
Gutiérrez García, Santiago (2015). “Arthurian Literature in Portugal”. Em David Hook (ed.), The Arthur of the Iberians. The Arthurian Legends in the Spanish and Portuguese Worlds, 58-117.

Laranjinha, Ana-Sofia (2012). "A matéria tristaniana do ciclo do Pseudo-Boron, da Suite du Merlin à Demanda do Santo Graal”. Em Lênia Márcia Mongelli (org.), De cavaleiros e cavalarias. Por terras de Europa e Américas, 101-109.

Longobardi, Monica (1992). "Nuovi frammenti della Post-Vulgata: la Suite du Merlin, la Continuazione della Suite du Merlin, la Queste e la Mort Artu (con l'intrusione del Guiron)". Studi Mediolatini e Volgari, XXXVIII, 118-155.

Longobardi, Monica (1987). "Frammenti di codici in antico francese della Biblioteca Comunale di Imola”. Cultura Neolatina, 47, 223-255.

Micha, Alexandre (1957). "Fragment de la Suite-Huth du Merlin". Romania, 78, $37-45$.

Miranda, José Carlos (1998). A Demanda do Santo Graal e o Ciclo Arturiano da Vulgata. Porto: Granito.

Morros, Bienvenido (1988). "Los problemas ecdóticos del Baladro del sabio Merlín". Em Vicente Beltrán (ed.), Actas del I Congresso de la Associanión Hispánica de Literatura Medieval, 457-471.

Pichel, Ricardo \& Varela Barreiro, Xavier (2017). "O fragmento galego-português do Livro de Tristam. Nova proposta cronolóxica e diatópica”. Madrygal. Revista de Estudios Gallegos, 20, 159-214.

Pickford, Cedric Edward (1960). L'évolution du roman arthurien en prose vers la fin $d u$ Moyen Âge d'après le manuscrit 112 du fond français de la Bibliothèque Nationale. Paris: A. G. Nizet.

Soberanas, Amadeu-J. (1979). "La version galaico-portuguaise de la Suite du Merlin”. Vox Romanica, 38, 174-193.

Sommer, Heinrich Oskar (1913). "Die Abenteuer Gawains, Ywains und Le Morholts mit den drei Jungfrauen aus der Trilogie (Demanda) des Pseudo-Robert de Boron die Fortsetzung des Huth-Merlin nach der allein bekannten HS. Nr. 112 der Pariser National Bibliothek Herausgegeben”. Beihefte zur Zeitschrift für romanische Philologie, 47, 1-134. Disponível em http://gallica.bnf.fr/ark:/12148/bpt6k24848j/ f2.image. $\mathrm{r}=\mathrm{H}+\mathrm{O}+$ Sommer.langPT(30.I.2019).

Trujillo, José Ramón (2014). "Literatura artúrica en la Península Ibérica: Cuestiones traductológicas y lingüísticas”. eHumanista, 28, 487-510.

Vinaver, Eugène (1949). "La genèse de la Suite du Merlin", Mélanges de Philologie romane et de Littérature médiévale offerts à Ernest Hoepffner. Paris: Belles Lettres. 


\section{Dicionários e base de dados}

Godefroy, Frédéric (1881-1902). Dictionaire de l'Ancienne Langue Française et de Tous ses Dialectes du IX $X^{e}$ au XV Siècle. Paris, F. Vieweg, Libraire-Éditeur. Disponível em http://www.lexilogos.com/francais dictionnaire ancien.htm (30.I.2019).

TMILG - Tesouro Medieval Informatizado da Lingua Galega. Disponível em https://ilg. usc.es/tmilg/ (30.I.2019).

PhiloBiblon, BITAGAP, BETA, Disponível em http://bancroft.berkeley.edu/philobiblon/ searchwork po.html (30.I.2019). 